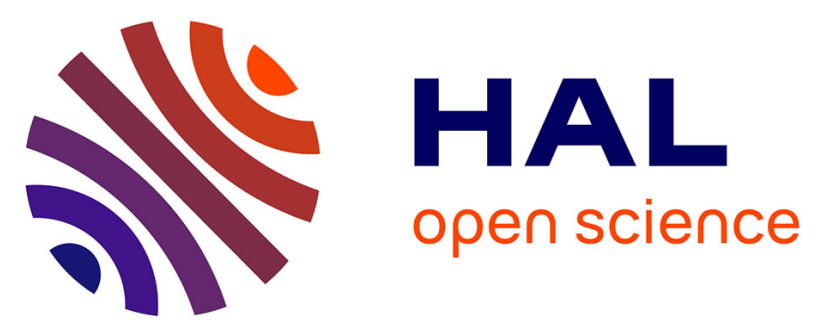

\title{
Direct Catalytic Conversion of Furfural to Furan-derived Amines in the Presence of Ru-based Catalyst
}

Shi Jiang, Wahiba Ghezali Ramdani, Eric Muller, Changru Ma, Titus Marc Pera, François Jerome, Karine de Oliveira Vigier

\section{- To cite this version:}

Shi Jiang, Wahiba Ghezali Ramdani, Eric Muller, Changru Ma, Titus Marc Pera, et al.. Direct Catalytic Conversion of Furfural to Furan-derived Amines in the Presence of Ru-based Catalyst. ChemSusChem, 2020, 13 (7), pp.1699-1704. 10.1002/cssc.202000003 . hal-03015522

\author{
HAL Id: hal-03015522 \\ https://hal.science/hal-03015522
}

Submitted on 19 Nov 2020

HAL is a multi-disciplinary open access archive for the deposit and dissemination of scientific research documents, whether they are published or not. The documents may come from teaching and research institutions in France or abroad, or from public or private research centers.
L'archive ouverte pluridisciplinaire HAL, est destinée au dépôt et à la diffusion de documents scientifiques de niveau recherche, publiés ou non, émanant des établissements d'enseignement et de recherche français ou étrangers, des laboratoires publics ou privés. 


\title{
Direct catalytic conversion of furfural to furan-derived amines in the presence of Ru based catalyst
}

\author{
Shi Jiang, ${ }^{[a, b]}$ Wahiba Ramdani, ${ }^{[a]}$ Eric Muller, ${ }^{[c]}$ Changru Ma,,${ }^{[b]}$ Marc Pera-Titus, ${ }^{[b]}$ François Jerôme, ${ }^{[a]}$ \\ and Karine De Oliveira Vigiera*[a]
}
[a] Dr. Shi Jiang, Dr. Wahiba Ramdani, Dr François Jérôme and Pr. Karine De Olivera Vigier IC2MP UMR CNRS_Université de Poitiers 7285
ENSIP 1 rue Marcel Doré, TSA 41195, 86073 Poitiers Cedex 9, France Email: karine.vigier@univ-poitiers.fr
[b] Dr. Changru Ma and Dr Marc Pera-Titus
Eco-Efficient Products and Processes Laboratory (E2P2L) UMI 3464 CNRS-Solvay 3966 Jin Du Road, Xin Zhuang Ind. Zone, 201108 Shanghai, China, Email: marc.pera-titus-ext@solvay.com

[c] Dr. Eric Muller

SOLVAY-Advanced Organic Chemistry \& Molecule Design Laboratory, Recherche \& Innovation Centre de Lyon 85 Avenue des Frères Perret, 69192 Saint Fons, France

Supporting information for this article is given via a link at the end of the document.

\begin{abstract}
The production of amine intermediates from biomass is capturing increasing attention. Herein we report simple and efficient preparation of I furan-derived amines (for instance 1-(furan-2-yl)-4methylpentan-2-amine) with high yield (up to $95 \%$ ) from (E)-1-(furan2-yl)-5-methylhex-1-en-3-one. The catalyst used was $\mathrm{Ru} / \mathrm{C}$ and it was recyclable up to 4th cycle. To further realize cost-efficiency, onereactor tandem concept was attempted. To this aim direct reaction from furfural was investigated. A high yield (74\%) towards 1-(furan-2yl)-4-methylpentan-2-amine could be achieved starting directly from furfural in the presence of methylisobutyl ketone, $\mathrm{NH}_{3}, \mathrm{H}_{2}$ and $\mathrm{Ru} / \mathrm{C}$ catalyst.
\end{abstract}

Lignocellulosic biomass is the most abundant, and inexpensive source of nonedible biomass that can be used for the synthesis of fuels and chemicals. ${ }^{1}$ Using chemo- or biocatalytic processes, a variety of oxygenates can be prepared from lignocellulose based on ethanol, diols, hexitols, furfural, aldehydes/ketones and organic acids among many others. ${ }^{2}$ However, the development of efficient catalytic reactions for the transformation of biomass into valuable nitrogen-containing chemicals is still challenging and starts to be an important goal of research programs. ${ }^{3}$ In particular, the development of simple and easily accessible catalytic systems to produce amines is an urgent need. ${ }^{4}$ Amines represent a privileged class of compounds with broad interest in chemical industry due to their nucleophilic properties, conferring them high reactivity. ${ }^{5-7}$ In particular, primary amines constitute valuable fine and bulk chemicals, which serve as versatile feedstocks and key intermediates for the synthesis of advanced chemicals, life science molecules and polymers. ${ }^{5,8-10}$ For example, furfurylamines from biomass-derived furfural can be used in diverse applications, including the preparation of polymers, biologically active compounds and as intermediates for the synthesis of pharmaceuticals such as antiseptic agents, antihypertensives and diuretics. ${ }^{11,12}$

Reductive amination of aldehydes or ketones for preparing primary amines is carried out at industrial level using heterogeneous catalysts based on supported $\mathrm{Cu},{ }^{13} \mathrm{Ni},{ }^{14} \mathrm{Pt},{ }^{15}$ $\mathrm{Ru},{ }^{10} \mathrm{Rh},{ }^{16} \mathrm{Pd},{ }^{17}$ due to their easy separation and recyclability, and lack of use of toxic reagents and/or stoichiometric reductants. ${ }^{18}$ In particular, reductive amination using $\mathrm{NH}_{3}$ and $\mathrm{H}_{2}$ has been explored in the field of Organic Chemistry, giving access to a variety of amines. ${ }^{4 e, 8,15,19}$ However, reductive amination reactions can suffer from overalkylation and the reduction of the aldehydes/ketones to alcohols, decreasing the selectivity to primary amines..$^{8-10,15,20,21}$ Hence, from an atom-economical and environmental standpoint, there is a need to develop selective and efficient catalysts for producing biobased primary amines, which is the prime task of this investigation.

Furfural, is a cheap furanic derivative $(1 \cdot 0-1.2 € / \mathrm{kg})$ available in large scale from carbohydrates ( $>200 \mathrm{kT} /$ year), making it an attractive raw material for the production of biobased chemicals. ${ }^{22}$ Recently, selective synthesis of biobased amines from furfural has attracted increasing attention. ${ }^{9,12,23,24}$ Here we report the preparation of a furan-derived primary amine [1-(furan-2-yl)-4methylpentan-2-amine, 2a] with high selectivity, starting first from the bioderived $[(E)-1$-(furan-2-yl)-5-methylhex-1-en-3-one, 1a] issued from the aldol condensation reaction of furfural with methyl isobutyl ketone (MIBK), using $\mathrm{NH}_{3}$ as nitrogen source, $\mathrm{H}_{2}$ as reducing agent and $5 \% \mathrm{Ru} / \mathrm{C}$ as catalyst. This molecule will find applications such as building-block for polymers, surfactants and solvents. The nature of the ketone used was also investigated. However, a special attention was given to the utilization of MIBK based on its used in the synthesis of furfural from xylose or xylan as an extraction agent. MIBK could be in that case an extraction agent and a reagent. Keeping in mind that the synthesis of furanic amine could be performed in the future from furfural obtained from hemicellulose, we further engineered a one-reactor tandem process by combining the basic Amberlyst-26 (catalyst 1) with $5 \% R u / C$ (catalyst 2) to access the functionalized amine $2 a$ starting directly from furfural (Scheme 1). This process encompasses two reactions, namely the aldol condensation of furfural with MIBK, and the reductive amination of the furanic 
ketone intermediate with $\mathrm{NH}_{3}$ and $\mathrm{H}_{2}$. This two steps process was also applied to other ketones (2-petanone and 2-heptanone).

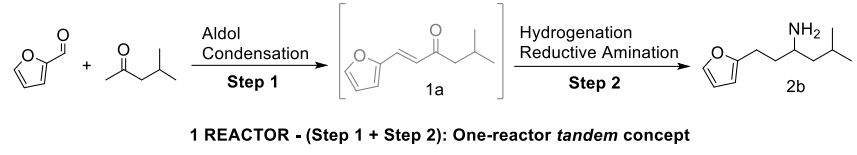

Scheme 1 Reaction pathway for the synthesis of 1-(furan-2-yl)-4-methylpentan2-amine (2a) from furfural.

Different types of carbonyl-conjugated vinylfurans can be selectively synthesized from furfural and ketones over solid basic catalysts. $^{25-27}$ Initially, (E)-1-(furan-2-yl)-5-methylhex-1-en-3-one (1a) was selected as model reagent. In 2015, $\mathrm{Ru} / \mathrm{Al}_{2} \mathrm{O}_{3}$ was reported as an active and selective catalyst for the reductive amination of aldehydes/ketones with $\mathrm{NH}_{3}$ and $\mathrm{H}_{2}$ to primary amines. ${ }^{28} \mathrm{Up}$ to $97 \%$ yield of 2 -nonylamine was achieved in the reductive amination of 2-nonanone after $10 \mathrm{~h}$, whereas $75 \%$ yield of furfurylamine was obtained starting from furfural after $2 \mathrm{~h}$ reaction. Based on these results, four $\mathrm{Ru}$ based catalysts were investigated. $\mathrm{Ru} / \mathrm{CeO}_{2}$ and $\mathrm{Ru} / \mathrm{H}-\mathrm{BEA}(5 \mathrm{wt} \% \mathrm{Ru}$ ) were prepared by incipient wetness impregnation using a precursor solution of aqueous $\mathrm{RuCl}_{3}$, while $\mathrm{Ru} / \mathrm{C}$ and $\mathrm{Ru} / \mathrm{Al}_{2} \mathrm{O}_{3}$ (5 wt\% $\mathrm{Ru}$ ) were obtained commercially. All the catalysts were pretreated under a $\mathrm{H}_{2} / \mathrm{Ar}$ flow at $200{ }^{\circ} \mathrm{C}$ before use. This temperature was chosen according to the reduction $\left(\mathrm{H}_{2}\right.$-TPR) profiles of the different catalysts, showing in all cases a main band in the range $60-120^{\circ} \mathrm{C}$ (Fig. S1). The Ru dispersion was determined by $\mathrm{CO}$ pulse chemisorption (Fig. S2). Ru/C exhibited the highest Ru dispersion (45\%), followed by $\mathrm{Ru} / \mathrm{CeO}_{2}$ (40\%) (Table 1). Besides, $\mathrm{Ru} / \mathrm{Al}_{2} \mathrm{O}_{3}$ and Ru/H-BEA show a Ru dispersion of $16 \%$ and $18 \%$, respectively. The average size of $R u$ nano-particles was in the range 1.7-2.0 nm measured by HR-TEM (Fig. S3 and S4).

Table 1. Metal dispersion and average size of Ru nanoparticles on the different catalysts used in this study

\begin{tabular}{lllll}
\hline Catalyst & $\mathrm{Ru} / \mathrm{C}$ & $\mathrm{Ru} / \mathrm{Al}_{2} \mathrm{O}_{3}$ & $\mathrm{Ru} / \mathrm{H}-\mathrm{BEA}$ & $\mathrm{Ru} / \mathrm{CeO}_{2}$ \\
\hline Ru dispersion (\%) ${ }^{[\mathrm{a}]}$ & 45 & 16 & 18 & 40 \\
Particle size (nm) $^{[\mathrm{b}]}$ & 1.7 & 2.0 & 2.0 & 2.0 \\
\hline
\end{tabular}

[a] $\mathrm{Ru}$ dispersion measured by CO-pulse chemisorption using a CO/Ru stoichiometry of 1 . [b] average Ru particle size $(\mathrm{nm})$ measured by TEM analysis.

The reductive amination of 1a was carried out in ethanol at 15 bar $\mathrm{H}_{2}$ and $\mathrm{NH}_{3}\left(0.3 \mathrm{~g}, \mathrm{NH}_{3} / 1 \mathrm{a}=10 / 1\right)$ over the different catalysts at $100{ }^{\circ} \mathrm{C}$ for $14 \mathrm{~h}$ (Table 2). In all these experiments, the conversion of $1 \mathrm{a}$ was above $99 \%$ after 20 min of reaction. When $\mathrm{Ru} / \mathrm{Al}_{2} \mathrm{O}_{3}$ catalyst was used ( $10 \mathrm{wt} \%$ with respect to $1 \mathrm{a}$ ), $78 \%$ and $12 \%$ yield of the furanic primary amine $\mathbf{2} \mathbf{b}$ and ketone $\mathbf{2 a}$ were obtained, respectively, with $90 \%$ carbon balance (entry 1, Fig. S5). Ru/HBEA exhibited a slightly lower performance with $67 \%$ and $20 \%$ yield of $\mathbf{2 b}$ and $\mathbf{2 a}$, respectively, and $87 \%$ carbon balance (entry 2). In the case of $\mathrm{Ru} / \mathrm{CeO}_{2}, \mathbf{2 b}$ and $\mathbf{2 a}$ were formed with $53 \%$ and $20 \%$ yield, respectively, as well as $8 \%$ yield of the THF-derived ketone (entry 3 ), but the carbon balance was lower (81\%). Finally, $\mathrm{Ru} / \mathrm{C}$ afforded the highest $\mathbf{2 b}$ yield ( $95 \%$, entry 4 ) with $96 \%$ carbon balance. On the guidance of the present results combined with the similar Ru dispersion and average particle size on the different catalysts, the support appears to play an important role on generating the furanic amine $\mathbf{2} \mathbf{b}$ with the selectivity evolving in the sense $\mathrm{C}>\mathrm{Al}_{2} \mathrm{O}_{3}>\mathrm{H}-\mathrm{BEA}>\mathrm{CeO}_{2}$.

Table 2. Catalyst screening for reductive amination of $1 a^{[a]}$

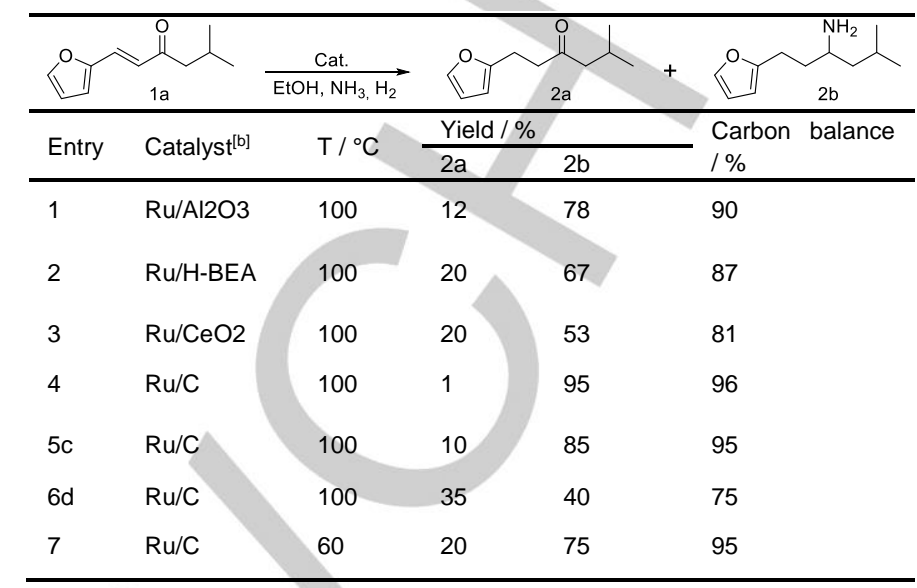

[a] Reaction conditions: $1 \mathrm{a}(0.3 \mathrm{~g}), \mathrm{EtOH}(1 \mathrm{~g}), \mathrm{NH} 3$ (0.3 g), H2 (15 bar), catalyst (30 mg), $100{ }^{\circ} \mathrm{C}, 14 \mathrm{~h}$; [b] The metal loading was $5 \mathrm{wt} \%$. The conversion was $>99 \%$ for all catalysts; [c] Catalyst $(15 \mathrm{mg})$; [d] Catalyst $(5 \mathrm{mg})$.

The acid properties of the different catalysts were characterized by $\mathrm{NH}_{3}$-TPD (Figure 1). H-BEA exhibited the strongest acid properties, as inferred by the large band appearing at a temperature higher than $400{ }^{\circ} \mathrm{C}$, potentially causing the degradation of the furan ring in the presence of water and in turn a carbon balance decrease. $\mathrm{Ru} / \mathrm{Al}_{2} \mathrm{O}_{3}$ showed a lower acid strength, while the acidity of $\mathrm{Ru} / \mathrm{CeO}_{2}$ and $\mathrm{Ru} / \mathrm{C}$ was even lower. In the case of $\mathrm{Ru} / \mathrm{C}$, an increasing trend of the signal was observed above $400{ }^{\circ} \mathrm{C}$, which can be attributed to partial decomposition of the carbon support. Based on all these characterizations, and according to the literature ${ }^{9}, \mathrm{Ru}$ on oxides with base sites, which act as electron-donating surfaces, can prevent reduction and reductive amination which is the case of $\mathrm{Ru}$ supported over $\mathrm{CeO}_{2}$. It was reported that an appropriate acidity can enhance the activation of carbonyl groups. In the case of $\mathrm{CeO}_{2}$-based catalyst, basic sites have negative effect and a repulsion may take places between the electron-rich substrate (1a or 2a unsaturated carbonyl compound) and the surface of $\mathrm{CeO}_{2}$, which leads to weaker adsorption and thus the decrease of the amine product selectivity. ${ }^{10}$ The support should be not a strong acid one and Ru should be well dispersed on the support to favour the reductive amination of the ketone $\mathbf{1 a}$.

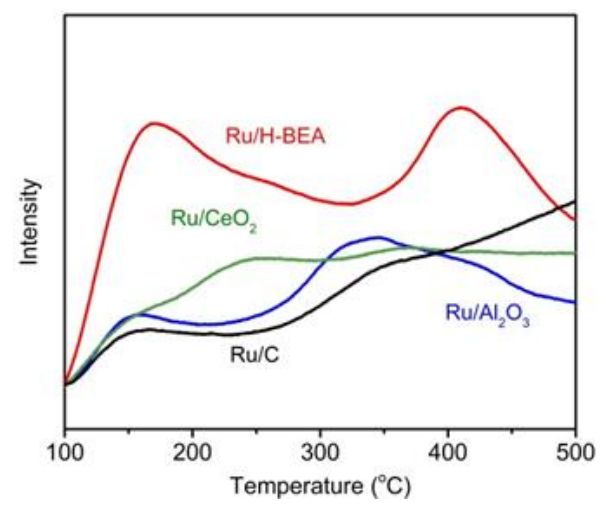

Figure 1. $\mathrm{NH}_{3}-\mathrm{TPD}$ profiles of different catalysts: $\mathrm{Ru} / \mathrm{H}-\mathrm{BEA}, \mathrm{Ru} / \mathrm{CeO}_{2}, \mathrm{Ru} / \mathrm{Al}_{2} \mathrm{O}_{3}$ and $\mathrm{Ru} / \mathrm{C}$. 
The $\mathrm{Ru} / \mathrm{C}$ catalyst loading was then decreased $10 \mathrm{wt} \%$ to $5 \mathrm{wt} \%$ (entry 5 ). A decrease of the $\mathbf{2 b}$ yield (from $96 \%$ to $85 \%$ ) was observed along with an increase of the $2 a$ yield from 1 to $10 \%$. A further decrease to $2.5 \mathrm{wt} \%$ (entry 6 ) resulted in $40 \%$ yield of $\mathbf{2 b}$ along with $35 \%$ yield of 2 a with $75 \%$ carbon balance. These results point out that $\mathbf{2 a}$ is a reaction intermediate and that depending on the catalyst loading, this can be converted into amine or not. Moreover, by increasing the reaction time, $2 \mathrm{a}$ could be converted into $\mathbf{2} \mathbf{b}$, but a longer reaction time led to product degradation and to a decrease of the carbon balance. A decrease of the temperature from $100{ }^{\circ} \mathrm{C}$ to $60{ }^{\circ} \mathrm{C}$ resulted in only $20 \%$ and $75 \%$ yield of $\mathbf{2 a}$ and $\mathbf{2 b}$, respectively, after $14 \mathrm{~h}$ reaction (entry 7 ).
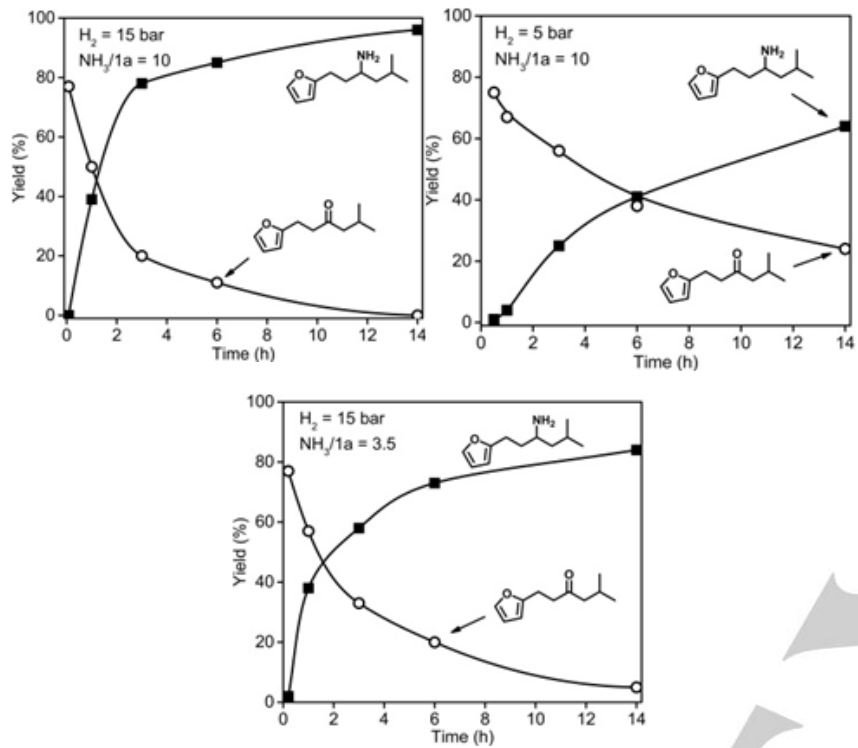

Figure 2. Kinetic profiles of the reductive amination of 1a over $\mathrm{Ru} / \mathrm{C}$; (a) catalyst (30 mg), 1a (0.3 g), EtOH (1 g), NH $3 / 1 \mathbf{a}=10 / 1, \mathrm{H}_{2}(15 \mathrm{bar}), 100^{\circ} \mathrm{C}, 14 \mathrm{~h}$; (b) catalyst $(30 \mathrm{mg}), 1 \mathrm{a}(0.3 \mathrm{~g}), \mathrm{EtOH}(1 \mathrm{~g}), \mathrm{NH}_{3} / \mathbf{1 a}=10 / 1, \mathrm{H}_{2}(5 \mathrm{bar}), 100{ }^{\circ} \mathrm{C}, 14$ h; (c) catalyst $(30 \mathrm{mg}), 1 \mathrm{a}(0.3 \mathrm{~g}), \mathrm{EtOH}(1 \mathrm{~g}), \mathrm{NH}_{3} / \mathbf{1 a}=3.5 / 1, \mathrm{H}_{2}(15 \mathrm{bar}), 100^{\circ} \mathrm{C}$ $14 \mathrm{~h}$.

It was thus interesting to evaluate the kinetic profile of the reductive amination of $\mathbf{1 a}$ in the presence of $\mathrm{Ru} / \mathrm{C}$ (Figure 2) under 15 bar $\mathrm{H}_{2}$ and using a $\mathrm{NH}_{3} / \mathbf{1}$ a molar ratio of $10: 1$. During the first $5 \mathrm{~min}$, 1a was rapidly converted into 2 a with a yield of $77 \%$ and $9 \%$ yield of the furanic imine, but only trace amounts of $\mathbf{2 b}$. The $\mathbf{2 b}$ yield increased gradually to $95 \%$ after $14 \mathrm{~h}$ at the expense of 2a. It appears from these results that, $\mathbf{1 a}$ is first converted into $\mathbf{2 a}$. In the presence of $\mathrm{NH}_{3}$, the furanic imine was generated, which was further hydrogenated to $\mathbf{2} \mathbf{b}$ (Scheme 2). Deep hydrogenated THF-derived ketone, amine and alcohol were detected only in trace amounts.

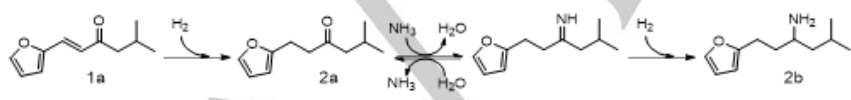

Scheme 2. Reaction pathway for the catalytic conversion of $\mathbf{1 a}$ into the furanic amine $\mathbf{2 b}$ over $\mathrm{Ru} / \mathrm{C}$

The effect of the $\mathrm{H}_{2}$ pressure and $\mathrm{NH}_{3} / \mathbf{1 a}$ molar ratio was further investigated in the presence of $\mathrm{Ru} / \mathrm{C}$. A decrease of the $\mathrm{H}_{2}$ pressure from 15 bar to 5 bar strongly influenced the initial formation rate of $\mathbf{2 b}(0.657 \mathrm{mmol}$ h- 1 vs. $0.067 \mathrm{mmol}$ h- 1 after 1 h), while the $\mathbf{2 b}$ yield decreased from $96 \%$ to $64 \%$ within the same reaction time. The maximum $2 \mathrm{a}$ yield was higher ( $24 \%$ vs $1 \%$ ) after $14 \mathrm{~h}$ reaction, while the carbon balance decreased from $96 \%$ to $88 \%$. A certain amount of $\mathrm{H}_{2}$ is required to fully convert $2 \mathrm{a}$ into 2b. In parallel, a decrease of the $\mathrm{NH}_{3} / 1$ a molar ratio from $10 / 1$ to $3.5 / 1$ resulted in a decline of the formation rate of $\mathbf{2 b}$ from 0.438 $\mathrm{mmol} \mathrm{h}-1$ to $0.326 \mathrm{mmol} \mathrm{h}^{-1}$, leading to slight decrease of the yield of $\mathbf{2} \mathbf{b}$ from 95 to $84 \%$. A certain amount of $\mathrm{NH}_{3}$ is required to carry out the reductive amination of $\mathbf{2 a}$ to $\mathbf{2} \mathbf{b}$. However, this can be decreased while keeping an interesting yield of $\mathbf{2} \mathbf{b}$, which it is not the case for the $\mathrm{H}_{2}$ pressure. Based on the reaction kinetics study, 15 bar $\mathrm{H}_{2}$ is required to achieve high yield of the furanic primary amine $\mathbf{2 b}$.

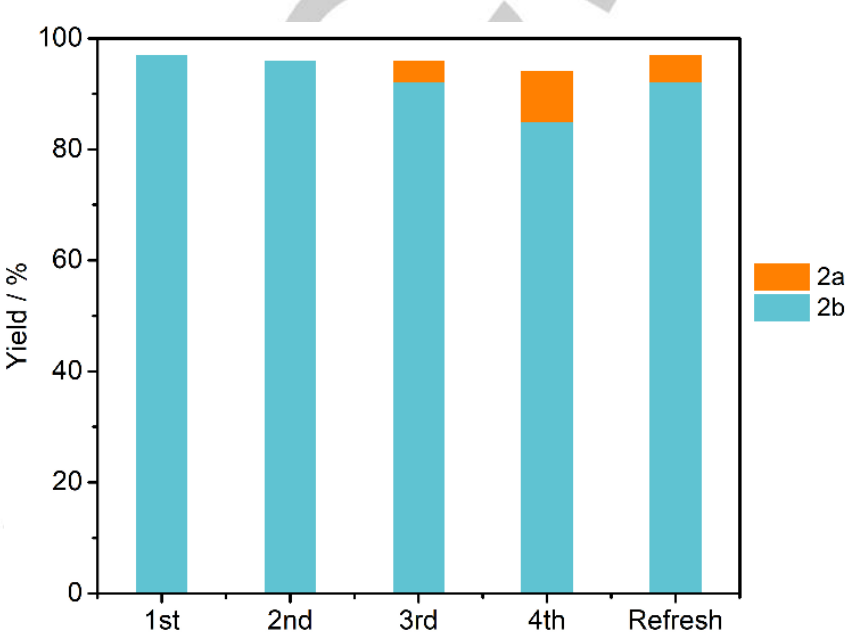

Figure 3. Catalytic performance of $\mathrm{Ru} / \mathrm{C}$ in consecutive runs in the reductive amination of 1a. Reaction conditions: $\mathrm{Ru} / \mathrm{C}(100 \mathrm{mg}), 1 \mathrm{a}(1 \mathrm{~g}), \mathrm{EtOH}(3 \mathrm{~g}), \mathrm{NH}_{3}$ $(1 \mathrm{~g}), \mathrm{H}_{2}$ (15 bar), $100^{\circ} \mathrm{C}, 14 \mathrm{~h}$.

The recyclability of Ru/C was further investigated (Figure 3). After each run, the catalyst was separated by centrifugation and was reused without any treatment. The yield of desired furanic amine remained constant after the 1 st and 2 nd runs, whereas a slight decrease of the amine yield by ca. $5 \%$ and $12 \%$ was obtained after the $3^{\text {rd }}$ and $4^{\text {th }}$ runs, with $4 \%$ and $9 \%$ yield of the furanic ketone, respectively. However, the carbon mass balance always kept around $95 \%$. In order to evaluate the reasons of this slight decrease, ICP analysis of the liquid phase were performed after each run and showed only slight metal leaching (Table 3).

Table 3. ICP analysis of the liquid phase after each run. Amount of $R u$ calculated in the solution

\begin{tabular}{lllll}
\hline & $1^{\text {st }}$ Cycle & $2^{\text {nd }}$ Cycle & $3^{\text {rd }}$ Cycle & $4^{\text {th }}$ Cycle \\
\hline Metal Ru $(\mathrm{ppm})$ & 14 & 43 & 53 & 44 \\
\hline
\end{tabular}

To assess if the leached species have catalytic activity, a reaction was performed and $\mathrm{Ru} / \mathrm{C}$ was recovered by hot filtration. In this experiment, the catalyst was removed from the reaction mixture after $1 \mathrm{~h}$ reaction at $100^{\circ} \mathrm{C}$. Then, the reaction was pursued with the filtrate for another $6 \mathrm{~h}$ and $13 \mathrm{~h}$ at $100^{\circ} \mathrm{C}$. No further formation of the furanic amine $\mathbf{2} \mathbf{b}$ was observed showing that even if there is a leaching of $R u$, the leached species were not active during the reaction and $\mathrm{Ru} / \mathrm{C}$ behaved as a truly heterogeneous catalyst (Fig. S6). Further characterizations of the catalysts were performed. TEM analysis of the fresh and four-times-used $\mathrm{Ru} / \mathrm{C}$ catalyst evidenced almost no difference in the average of $\mathrm{Ru}$ 
particle size (Fig. S3). However, the Ru dispersion of the recycled $\mathrm{Ru} / \mathrm{C}$ decreased from $45 \%$ to $8 \%$, suggesting a sintering of $\mathrm{Ru}$ particles (Fig. S2). The used catalyst was washed with ethanol, dried at $80^{\circ} \mathrm{C}$ under vacuum for overnight, and reduced again under $\mathrm{a}_{2} / \mathrm{Ar}$ flow. The refreshed catalyst was reused using the same experimental conditions.

We were pleased to see that the yield of product $\mathbf{2} \mathbf{b}$ increased to $92 \%$. This result confirms that the integrity of the catalyst was kept during the reaction and that it could be reused after some treatment due to the absorption of side products on its surface. TGA analysis of fresh catalyst and recovered catalyst after washing with ethanol and drying confirms this result. Similar weight loss were observed between the fresh $\mathrm{Ru} / \mathrm{C}$ and the washed with ethanol and dried catalyst (Fig. S8, S9).

Table 4 Production of bio-based amines over $\mathrm{Ru} / \mathrm{C}$ catalyst

Entry Substrate Yield /\%

Reaction conditions: Ru/C (30 mg), EtOH (1 g), NH3 (0.3 g), H2 (15 bar), $100^{\circ} \mathrm{C}$; Acetophenone $(0.3 \mathrm{~g}), 1.5 \mathrm{~h}$; furanic ketone $(0.3 \mathrm{~g})$, entries 1-3: reaction time of $6 \mathrm{~h}$ and entries $4-5$ reaction time $14 \mathrm{~h}$.

To evaluate the generality of $\mathrm{Ru} / \mathrm{C}$, we extended the scope for aldol condensation reaction, other ketones were investigated (2pentanone, 2-heptanone, benzaldehyde, 2,5-hexanedione) and the yield obtained were respectively $93,94,78$ and $84 \%$ of the aldol compound. For reductive amination the scope was also investigated (Table 4) and the corresponding amines were obtained with high yield. In the case of benzaldehyde the byproduct formed was bis(1-phenylethyl)amine. In the presence of hexanedione, a cyclization occurs to produce pyrrole as was reported by Johannes $\mathrm{G}$. de Vries et al. ${ }^{29}$ with the formation of 2 (2-(furan-2-yl)vinyl)-5-methyl-1H-pyrrole(28\%) and 2-(2-(furan-2yl)ethyl)-5-methyl-1H-pyrrole (65\%). These results confirm that $\mathrm{Ru} / \mathrm{C}$ enables a selective synthesis of bio-based primary amines and with the possibility to produce pyrrole.

To access bio-based amines in a suitable way, the catalytic system was extended to a process starting from furfural and directly combining first an aldol condensation reaction with sequential reductive amination in a single reactor (Scheme 3).

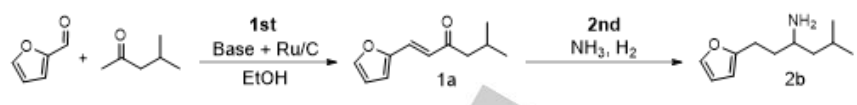

Scheme 3 One-reactor synthetic strategy for the synthesis of furan-derived amines starting from furfural.

First, MIBK was used as a ketone and to prevent the amination of MIBK, the optimization of the aldol condensation reaction between furfural and MIBK (equimolar ratio) over A26 was investigated. A yield up to $91 \%$ of 1 a was achieved at $100^{\circ} \mathrm{C}$ after $4 \mathrm{~h}$ reaction with the $98 \%$ furfural conversion (Fig. S7). A mechanical mixture of $\mathrm{A} 26$ and $\mathrm{Ru} / \mathrm{C}$ was further added to the reactor and a promising $90 \%$ yield of 1 a was achieved at $100{ }^{\circ} \mathrm{C}$ for $4 \mathrm{~h}$ in ethanol with an equimolar furfural/MIBK mixture. After 4 $h$ for promoting the aldol condensation of furfural with MIBK, $\mathrm{NH}_{3}$ $(0.3 \mathrm{~g})$ and $\mathrm{H}_{2}$ (15 bar) were added to the reactor. A $\mathbf{2 b}$ yield up to $71 \%$ was achieved after $20 \mathrm{~h}$ reaction (Figure 4). To increase the $\mathbf{2} \mathbf{b}$ yield, the reaction time and the $\mathrm{H}_{2}$ pressure were further optimized (Table 5). When the reaction time was prolonged to 24 h (entry 3), or the $\mathrm{H}_{2}$ pressure was increased to 30 bar (entry 4), the $\mathbf{2 b}$ yield reached a similar value $(74 \%)$ with the concomitant formation of $\mathbf{2 a}$. Compared with the maximum theoretical yield $(91 \%)$, the decrease in the yield for the one-reactor process might be attributed to the degradation of furfural or intermediates during both reactions. However, a high $\mathbf{2} \mathbf{b}$ yield could be obtained from furfural.

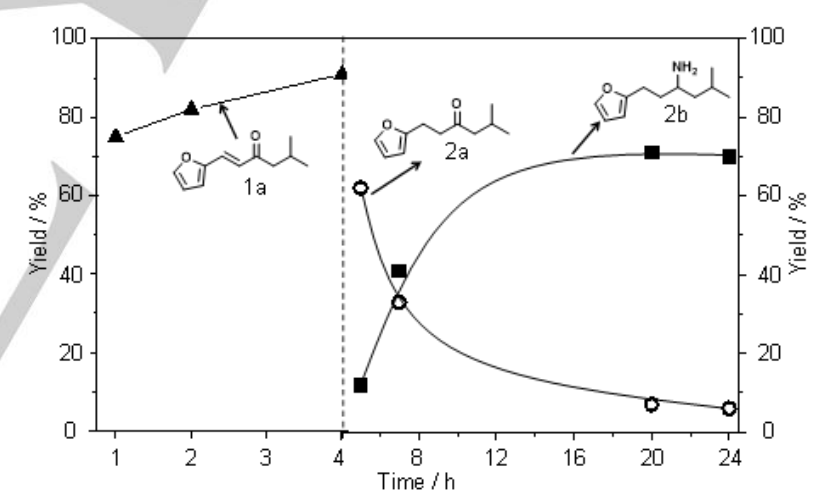

Figure 4. Kinetics of the one-reactor process using a mechanical mixture of A26 and $\mathrm{Ru} / \mathrm{C}$. Reaction conditions: furfural (162 mg, $1.69 \mathrm{mmol})$, MIBK (169 mg, $1.69 \mathrm{mmol})$, ethanol $(1 \mathrm{~g}), \mathrm{A} 26(64.8 \mathrm{mg}), \mathrm{Ru} / \mathrm{C}(30 \mathrm{mg}), 100^{\circ} \mathrm{C}$. First step: $4 \mathrm{~h}$. Second step: $\mathrm{NH}_{3}(0.3 \mathrm{~g}), \mathrm{H}_{2}$ (15 bar), variable time.

Secondly, it was interesting to evaluate the scope of the ketone used in the combination of an aldol condensation reaction with sequential reductive amination in a single reactor. 2-pentanone and 2-heptanone were investigated to perform aldol condensation and reductive amination reactions in a two steps one single reactor (Table 5 , entries 6,7 ). The aldol condensation reaction was $1 \mathrm{~h} 30$ for these two ketones. We were pleased to see that in the presence of 2-pentanone, $25 \%$ of furanic amine was obtained and that from 2-heptanone $57 \%$ of furanic amine was observed showing that this strategy can be applied to other ketones than MIBK. However, a full study has to be performed for each ketone in order to improve the yield. 
Table 5. Catalytic conversion of furfural to furanic amine by one-reactor, two-step process ${ }^{[a]}$

\begin{tabular}{|c|c|c|c|c|c|c|c|c|c|c|c|}
\hline \multirow[b]{2}{*}{ Entry } & \multirow[b]{2}{*}{ Reagent } & \multirow[t]{2}{*}{ Ketone } & \multirow[b]{2}{*}{ Catalyst } & \multicolumn{3}{|c|}{ Time } & \multirow[b]{2}{*}{$\begin{array}{l}\mathrm{NH}_{3} \\
/ \mathrm{g}\end{array}$} & \multirow[b]{2}{*}{$\mathrm{H}_{2} / \mathrm{bar}$} & \multicolumn{2}{|l|}{ Yield / \% } & \multirow[t]{2}{*}{ Carbon balance / \% } \\
\hline & & & & $1^{\text {st }}$ & & $2^{\text {nd }}$ & & & $\begin{array}{l}\text { Unsaturated } \\
\text { furanic } \\
\text { ketone }\end{array}$ & Amine & \\
\hline 1 & $1 \mathbf{a}$ & - & $\mathrm{Ru} / \mathrm{C}$ & & 14 & & 0.3 & 15 & $<1(2 a)$ & $95(\mathbf{2 b})$ & 95 \\
\hline 2 & Furfural & MIBK & $\mathrm{Ru} / \mathrm{C}+\mathrm{A} 26$ & 4 & & 16 & 0.3 & 15 & $7(\mathbf{2 a})$ & $71(2 b)$ & 78 \\
\hline 3 & Furfural & MIBK & $\mathrm{Ru} / \mathrm{C}+\mathrm{A} 26$ & 4 & & 24 & 0.3 & 15 & $6(2 a)$ & $70(\mathbf{2 b})$ & 76 \\
\hline 4 & Furfural & MIBK & $\mathrm{Ru} / \mathrm{C}+\mathrm{A} 26$ & 4 & & 16 & 0.3 & 30 & $3(2 a)$ & $74(2 b)$ & 77 \\
\hline 5 & Furfural & MIBK & $\mathrm{Ru} / \mathrm{C}+\mathrm{A} 26$ & & 14 & & 0.3 & 15 & $18(2 a)$ & $9(\mathbf{2 b})$ & 27 \\
\hline $6^{[b]}$ & Furfural & 2-pentanone & $\mathrm{Ru} / \mathrm{C}+\mathrm{A} 26$ & 1.5 & & 6 & 0.3 & 15 & 33 & $25(3 \mathbf{b})$ & 58 \\
\hline $7[b]$ & Furfural & 2-heptanone & $\mathrm{Ru} / \mathrm{C}+\mathrm{A} 26$ & 1.5 & & 14 & 0.3 & 15 & & $57(4 b)$ & 80 \\
\hline
\end{tabular}

[a] The furfural conversion was $100 \%$ for all the reactions. (1st) All runs were carried out at $100{ }^{\circ} \mathrm{C}$ in $1 \mathrm{~g}$ EtOH with $162 \mathrm{mg}$ furfural while keeping the molar ratio of ketone:furfural - 1:1 and the mass ratio of base/furfural $40 \mathrm{wt} \%, 30 \mathrm{mg} \mathrm{Ru} / \mathrm{C}$; (2nd) the reductive amination reactions were all following the first step of aldol condensation by inserting $\mathrm{NH}_{3}$ and $\mathrm{H}_{2}$.[b] not optimized result.

In summary, we demonstrated that a new family of furan-derived primary amines could be selectively prepared (95\%) from bioderived ketones using $\mathrm{NH}_{3}$ as a nitrogen source, molecular $\mathrm{H} 2$ as a reducing agent and commercially available $\mathrm{Ru} / \mathrm{C}$ as catalyst. This system efficiently catalyzed the hydrogenation of $\mathrm{C}=\mathrm{C}$ bonds together with the reductive amination of carbonyl groups at mild reaction conditions. Besides, the catalyst remains stable during the reaction for at least 4 consecutive runs. We also demonstrated that furfural could be directly converted into furan-derived primary amines by a one-reactor two-step process, achieving a high yield of $74 \%$ and that it can be extended to other ketones than MIBK (not optimized results). Thus our present work leads to the production of opens a new avenue for producing biomass-derived amines from products of biomass processing with potential application as biosolvents or biosurfactants. Also, this work provides a toolbox that enables the conversion of furfural into the desired amine. The deposition of ruthenium species over a multifunctional support, the design of a continuous flow process and the transposition of the current results to a variety of amines are topics under investigation.

\section{Acknowledgements ((optional))}

The authors would like to thank the French ANR agency for the funding of FurCab Project ANR-15-CE07-0016. The authors are also grateful to the Région Nouvelle Aquitaine for the funding of this project through the FR CNRS INCREASE 3707, the chair TECHNOGREEN and FEDER.

Keywords: Amines $•$ Biomass $•$ Catalyst $・$ Furfural $•$ Ketones

[1] a) M. Dusselier, M. Mascal, B. F. Sels, Top. Curr. Chem. 2014, 353, 140; b) D. M. Alonso, J. Q. Bond and J. A. Dumesic, Green Chem. 2010, 12, 1493-1513; c) P. Anastas, N. Eghbali, Chem. Soc. Rev. 2010, 39, 301-312; d) A. A. Koutinas, C. Du, R. H. Wang, C. Webb, Introduction to Chemicals from Biomass, Wiley, Hoboken, 2008; e) Y. Ogiwara, T. Uchiyama, N. Sakai, Angew. Chem. Int. Ed. 2016, 55, 1864-1867.
[2] a) J. Lange, Angew. Chem. Int. Ed. 2015, 54, 13186-13197; b) A. Wang T. Zhang, Acc. Chem. Res. 2013, 46, 1377-1386; c) N. Ji, T. Zhang, M. Zheng, A. Wang, H. Wang, X. Wang, J. G. Chen, Angew. Chem. Int. Ed. 2008, 47, 8510-8513.

[3] a) N. Yan, X. Chen, Nature 2015, 524, 155-157; b) J. Zhang, N. Yan Green Chem. 2016, 18, 5050-5058; c) S. Imm, S. Bahn, M. Zhang, L. Neubert, H. Neumann, F. Klasovsky, J. Pfeffer, T. Haas, M. Beller, Angew. Chem. Int. Ed. 2011, 50, 7599-7603; d) M. Pelckmans, W. Vermandel, F. V. Waes, K. Mooen, B. F. Sels, Angew. Chem. Int. Ed. 2017, 56, 14540-14544.

[4] a) S. A. Gomez, J. A. Peters, T. Maschmeyer, Adv. Synth. Catal., 2002 344, 1037; b) H. Alinezhad, H. Yavari, F. Salehian, Curr. Org. Chem., 2015, 19, 1021; c) V. N. Wakchaure, J. Zhou, S. Hoffmann, B. List Angew. Chem. Int. Ed., 2010, 49, 4612; d) K. Natte, H. Neumann, R. V Jagadeesh, M. Beller, Nat. Commun., 2017, 8, 1344; e) R. V. Jagadeesh, K. Murugesan, A. S. Alshammari, H. Neumann, M. Pohl, J. Radnik, M. Beller, Science, 2017, 358, 326.

[5] A. Ricci, Amino Group Chemistry: From Synthesis to the Life Sciences, Wiley-VCH, 2008.

[6] S. D. Roughley, A. M. Jordan, J. Med. Chem. 2011, 54, 3451-3479

[7] C. Joyce, W. F. Smyth, V. N. Ramachandran, E. O'Kane, D. J. Coulter, J. Pharm. Biomed. Anal. 2004, 36, 465-476.

[8] T. Senthamarai, K. Murugesan, J. Schneidewind, N. V. Kalevaru, W. Baumann, H. Neumann, P. C. J. Kamer, M. Beller, R. V. Jagadeesh, Nat. Commun. 2018, 9, 4123-4134.

[9] T. Komanoya, T. Kinemura, Y. Kita, K. Kamata, M. Hara, J. Am. Chem. Soc. 2017, 139, 11493-11499.

[10] a) G. Liang, A. Wang, L. Li, G. Xu, N. Yang, T. Zhang, Angew. Chem. Int. Ed. 2017, 56, 3050-3054; b) J. Kijenski, P. Winiarek, T. Paryjczak, A Lewicki, A. Mikołajska, Appl. Catal. A: Gen., 2002, 233, 171-182.

[11] M. Pelckmans, T. Renders, S. Van de Vyver, B. F. Sels, Green Chem. 2017, 19, 5303-5331.

[12] J. A. T. Caetano, A. C. Fernandes, Green Chem. 2018, 20, 2494-2498.

[13] K. V. R. Chary, K. K. Seela, D. Naresh, P. Ramakanth, Catal. Commun. 2008, 9, 75-81.

[14] C. F. Winans, J. Am. Chem. Soc. 1939, 61, 3566-3567.

[15] Y. Nakamura, K. Kon, A. S. Touchy, K. Shimizu, W. Ueda, ChemCatChem 2015, 7, 921-924.

[16] M. Chatterjee, T. Ishizaka, H. Kawanami, Green Chem. 2016, 18, 487 495.

[17] A. W. Heinen, J. A. Peters, H. Bekkum, Eur. J. Org. Chem. 2000, 13, 2501-2506.

[18] a) J. L. Klinkenberg and J. F. Hartwig, Angew. Chem. Int. Ed. 2011, 50, 86-95; b) J. Kim, H. J. Kim, S. Chang, Eur. J. Org. Chem. 2013, 16, 3201 3213 
[19] T. Gross, A. Seayad, M. Ahmad, M. Beller, Org. Lett. 2002, 4, 2055-2058.

[20] S. Ogo, K. Uehara, T. Abura, S. Fukuzumi, J. Am. Chem. Soc. 2004, 126, 3020-3021.

[21] J. Gallardo-Donaire, M. Ernst, O. Trapp, T. Schaub, Adv. Synth. Catal. 2016, 358, 3-25.

[22] a) R. Mariscal, P. Maireles-Torres, M. Ojeda, I. Sádaba, M. López Granados, Energy Environ. Sci. 2016, 9, 1144-1189; b) X. Li, P. Jia, T. Wang, ACS Catal. 2016, 6, 7621-7640; c) J.-P. Lange, E. van der Heide, J. van Buijtenen, R. Price, ChemSusChem 2012, 5, 150-156; c) S.Jiang, C. Ma, E. Muller, M. Pera-Titus, F. Jérôme, K. De Oliveira Vigier, ACS Catal. 2019, 9, 8893-8902.

[23] D. Chandra, Y. Inoue, M. Sasase, M. Kitano, A. Bhaumik, K. Kamata, H. Hosono, M. Hara, Chem. Sci. 2018, 9, 5949-5956.

[24] V. M. S. Isca and A. C. Fernandes, Green Chem. 2018, 20, 3242-3245.

[25] G. Liang, A. Wang, X. Zhao, N. Lei and T. Zhang, Green Chem. 2016, 18, 3430-3433.

[26] R. Garro, M. Navarro, J. Primo and A. Corma, J. Catal. 2005, 233, 342 350.

[27] M. J. Climent, A. Corma, H. Garcia, R. Guil-Lopez, S. Iborra and V. Fornés, J. Catal. 2001, 197, 385-393.

[28] B. Dong, X. Guo, B. Zhang, X. Chen, J. Guan, Y. Qi, S. Han, X. Mu, Catal. 2015, 5, 2258-2270.

[29] B. Wozniak, S. Tin and J. G. de Vries, Chem. Sci. 2019, 10, 6024-6034. 


\section{Entry for the Table of Contents}

Insert graphic for Table of Contents here. ((Please ensure your graphic is in one of following formats))

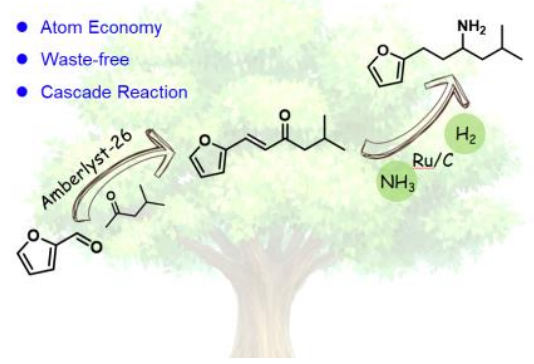

Catalytic conversion of furfural to primary amines with high yield (74\%) by a one-reactor two-step process in the presence of Amberlyst 16 and $\mathrm{Ru} / \mathrm{C}$ based catalysts. The hydrogenation of $\mathrm{C}=\mathrm{C}$ bonds together with the reductive amination of carbonyl groups at mild reaction conditions were performed using ammonia and hydrogen. 